\title{
Glutathione S-transferase P1 (GSTP1) suppresses cell apoptosis and its regulation by $m i R-133 a$ in head and neck squamous cell carcinoma (HNSCC)
}

\author{
MURADIL MUTALLIP ${ }^{1,2}$, NIJIRO NOHATA ${ }^{1,2}$, TOYOYUKI HANAZAWA ${ }^{2}$, NAOKO KIKKAWA ${ }^{1,2}$, \\ SHIGETOSHI HORIGUCHI ${ }^{2}$, LISA FUJIMURA ${ }^{3}$, KAZUMORI KAWAKAMI ${ }^{4}$, TAKESHI CHIYOMARU ${ }^{4}$, \\ HIDEKI ENOKIDA ${ }^{4}$, MASAYUKI NAKAGAWA ${ }^{4}$, YOSHITAKA OKAMOTO ${ }^{2}$ and NAOHIKO SEKI ${ }^{1}$ \\ Departments of ${ }^{1}$ Functional Genomics, ${ }^{2}$ Otorhinolaryngology/Head and Neck Surgery, Graduate School \\ of Medicine, and ${ }^{3}$ Biomedical Research Center, Chiba University, Chiba; ${ }^{4}$ Department of Urology, \\ Graduate School of Medical and Dental Sciences, Kagoshima University, Kagoshima, Japan
}

Received September 30, 2010; Accepted November 16, 2010

DOI: $10.3892 / \mathrm{ijmm} .2010 .589$

\begin{abstract}
The glutathione S-transferase P1 (GSTP1) protein plays several critical roles in both normal and neoplastic cells, including phase II xenobiotic metabolism, stress responses, signaling and apoptosis. Overexpression of GSTP1 has been observed in many types of cancer, including head and neck squamous cell carcinoma (HNSCC). However, the role of GSTP1 in HNSCC is not well understood. We investigated the role of GSTP1 in two HNSCC cell lines, HSC3 and SAS. Silencing of GSTP1 revealed that cancer cell proliferation was significantly decreased in both cell lines. In addition, the frequency of apoptotic cells increased following si-GSTPI transfection of HSC3 and SAS cell lines. Growing evidence suggests that microRNAs (miRNAs) negatively regulate gene expression and can function as oncogenes or tumor suppressors in human cancer. Based on the results of web-based searches, $m i R-133 a$ is a candidate miRNA targeting GSTP1. Down-regulation of $m i R-133 a$ has been reported in many types of human cancer, including HNSCC. Transient transfection of $m i R-133 a$ repressed the expression of GSTP1 at both the mRNA and protein levels. The signal from a luciferase reporter was significantly decreased at one $m i R-133 a$ target site at the 3'UTR of GSTP1, suggesting that $m i R-133 a$ directly regulates GSTP1. Our data indicate that GSTP1 may have an oncogenic function and may be regulated by $m i R-133 a$, a tumor suppressive miRNA in HNSCC. The identification of a novel oncogenic pathway could provide new insights into potential mechanisms of HNSCC carcinogenesis.
\end{abstract}

Correspondence to: Dr Naohiko Seki, Department of Functional Genomics, Chiba University Graduate School of Medicine, 1-8-1 Inohana Chuo-ku, Chiba 260-8670, Japan

E-mail: naoseki@faculty.chiba-u.jp

Key words: miR-133a, head and neck squamous cell carcinoma, glutathione S-transferase P1, apoptosis

\section{Introduction}

Head and neck squamous cell carcinoma (HNSCC) constitutes the sixth most common malignancy worldwide (1). In spite of considerable advances in surgery, radiotherapy and chemotherapy, the overall five-year survival rate for patients with this type of cancer is among the lowest of all major cancer types and has not improved dramatically during the last decade (2). Local tumor recurrence and distant metastasis after conventional therapy appear to be major contributing factors decreasing survival of HNSCC patients. Therefore, understanding the molecular oncogenic pathways underlying HNSCC would be helpful to improve diagnosis, therapy, and prevention of the disease.

Glutathione S-transferase P1 (GSTP1), a member of the GST enzyme superfamily, catalyzes the conjugation of electrophiles to glutathione in the process of detoxification (3). Recently, we demonstrated that GSTPI is highly expressed in human HNSCC tissue (4) and is frequently overexpressed in many other cancers, including tumors of the brain, breast, ovary, esophagus, stomach, pancreas, colon, skin, kidney, lung, bile ducts, bladder and lymphatic and hematopoietic systems (5-10). As such, there has been considerable clinical interest in GSTPI as a tumor marker and as a therapeutic target $(11,12)$. However, little is known about the functional role of GSTP1 in HNSCC.

microRNAs (miRNAs), are endogenous small non-coding RNAs (19-22 nucleotides) that can control gene expression by targeting mRNAs for cleavage or translational repression (13). Bioinformatic predictions indicate that miRNAs regulate more than $30 \%$ of the protein coding genes (14). It is estimated that approximately 1,000 miRNAs exist in the vertebrate genome. Release 16.0 of the miRBase database (http://microrna.sanger. ac.uk/) included 1,048 registered human miRNAs. Growing evidence suggests that miRNAs are involved in several crucial biological processes, including development, differentiation, apoptosis, and proliferation $(13,15)$. Furthermore, miRNAs can function either as oncogenes or tumor suppressors and are aberrantly expressed in several types of human cancer (16-18). 
A search of the TargetScanHuman release 5.1 database, identified $m i R-133 a$ as a candidate miRNA regulator of GSTP1. Down-regulation of miR-133a has been reported in many types of human cancer, including HNSCC (19-22). More recently, we demonstrated that miR-133a functions as a tumor suppressor in esophageal cancer and bladder cancer $(23,24)$. In this study, we conducted a functional analysis of GSTPI and investigated whether GSTP1 is directly regulated by $m i R-133 a$ in HNSCC cell lines. The identification of a novel oncogenic pathway could provide new insights into potential mechanisms of HNSCC carcinogenesis.

\section{Materials and methods}

Clinical HNSCC specimens. Twenty pairs of HNSCC (oral cavity, $n=9$; $\operatorname{larynx}, n=3$; oropharynx, $n=3$; hypopharynx $\mathrm{n}=5$ ) and corresponding normal epithelial samples were obtained from patients at the Chiba University Hospital (Chiba, Japan) from 2007 to 2009. All tissue specimens were obtained from patients undergoing surgical treatment. Normal tissues were obtained far from the center of the cancer. No cancer cells were detected in neighboring formalinfixed, paraffin-embedded tissues. Written consent of tissue donation for research purposes was obtained from each patient before tissue collection. The protocol was approved by the Institutional Review Board of Chiba University. The specimens were immersed in RNAlater (Qiagen, Valencia, CA, USA) and stored at $-20^{\circ} \mathrm{C}$ until RNA was extracted.

HNSCC cell culture. Human HNSCC cell lines (HSC3 and SAS) were provided by the American Type Culture Collection (ATCC, Manassas, VA, USA). Both cell lines were grown in Dulbecco's Modified Eagle's Medium/Nutrient Mixture F-12 Ham (DMEM/F-12) supplemented with $10 \%$ fetal bovine serum in a humidified atmosphere containing $5 \% \mathrm{CO}_{2}$ at $37^{\circ} \mathrm{C}$. HSC3 was derived from a lymph node in tongue squamous cell carcinoma, while SAS came from a primary region of tongue squamous cell carcinoma.

RNA isolation. Total RNA was isolated using TRIzol reagent (Invitrogen, Carlsbad, CA) according to the manufacturer's protocol. RNA concentrations were determined spectrophotometrically, and the molecule integrity was checked by gel electrophoresis. RNA quality was confirmed using an Agilent 2100 Bioanalyzer (Agilent Technologies, Santa Clara, CA).

Real-time quantitative RT-PCR. First-strand cDNA was synthesized from $1 \mu \mathrm{g}$ total RNA using random primers and the Reverse Transcription (RT) system (Promega, Tokyo, Japan). Gene-specific PCR products were continuously assayed using a 7900-HT real-time PCR System according to the manufacturer's protocol (Applied Biosystems, Foster City, CA, USA). The initial PCR step consisted of a 10 min hold at $95^{\circ} \mathrm{C}$, followed by 40 cycles consisting of a $15 \mathrm{sec}$ denaturation at $95^{\circ} \mathrm{C}$ and a $1 \mathrm{~min}$ annealing/extension at $63^{\circ} \mathrm{C}$. TaqMan ${ }^{\circledR}$ probes and primers for GSTPI (P/N: Hs00168310_m1) and the GAPDH (A/N: NM_002046) internal control were obtained from Applied Biosystems (Assay-On-Demand gene expression products). The expression levels of $m i R-133 a(\mathrm{P} / \mathrm{N}$ : 002246) were analyzed by TaqMan quantitative real-time PCR
(TaqMan ${ }^{\circledR}$ MicroRNA Assay; Applied Biosystems) and normalized to RNU48 (A/N: X96648). All reactions were performed in triplicate, and included negative control reactions that lacked cDNA.

Immunoblotting and immunohistochemistry. Cells were harvested $72 \mathrm{~h}$ after transfection and lysates were prepared. Fifty $\mu \mathrm{g}$ of protein from cell lysates were separated by NuPAGE on 4-12\% Bis-Tris gels (Invitrogen) and transferred to PVDF membranes. Immunoblotting was performed with diluted (1:100) monoclonal GSTP1 antibody (ab47709, Abcam, Cambridge, UK). The $\beta$-actin antibody (sc-1615; Santa Cruz Biotechnology, Santa Cruz, CA, USA) was used as an internal control. The membrane was washed and incubated with goat anti-mouse IgG (H+L)-HRP conjugate (Bio-Rad, Hercules, CA, USA). Specific complexes were visualized by echochemiluminescence (GE Healthcare Bio-Sciences, Princeton, NJ, USA).

For immunohistochemistry, primary mouse monoclonal antibodies against GSTP1 (Cell Signaling) were diluted 1:200. The slides were treated with biotinylated anti-mouse IgG $(\mathrm{H}+\mathrm{L})$ made in house (Vector Laboratories, Burlingame, CA, USA). Diaminobenzidine-hydrogen peroxide (Sigma-Aldrich, St. Louis, MO, USA) was the chromogen, and counterstaining was carried out with $0.5 \%$ hematoxylin.

si-GSTP1 and mature miRNA transfection in HNSCC cell lines. As described previously $(24,25)$, si-GSTP1 and si-control molecules were transfected into the HNSCC cell lines with Opti-MEM (Invitrogen) and Lipofectamine ${ }^{\mathrm{TM}}$ RNAiMax reagent (Invitrogen). After co-transfecting $10 \mathrm{nM}$ small interfering RNA, si-GSTPI (P/N: s194476; Applied Biosystems) or si-control (D-001810-10; Thermo Fisher Scientific), HNSCC cells were seeded into 96 -well plates at $3 \times 10^{3}$ cells per well for proliferation assays or 6-well plates at $3 \times 10^{4}$ for apoptosis assays.

Mature miRNA molecules, Pre-miR ${ }^{\mathrm{TM}}$ miRNA precursors, and a negative control (Applied Biosystems, Foster City, CA, USA) were incubated with Opti-MEM (Invitrogen) and Lipofectamine $^{\mathrm{TM}}$ RNAiMax reagent (Invitrogen) as previously described $(24,25)$. We first confirmed the transfection efficiency of Pre-miR ${ }^{\mathrm{TM}}$ in cell lines, based on the down-regulation of PTK 9 mRNA by transfection with $m i R-l$ (as recommended by the manufacturer).

Cell proliferation assay. Cells were transfected with $10 \mathrm{nM}$ siRNA or miRNA by reverse transfection and plated in 96-well plates at $3 \times 10^{3}$ cells per well. After 72 or $96 \mathrm{~h}$, cell proliferation was determined by the XTT assay, using the Cell Proliferation kit II (Roche Molecular Biochemicals, Mannheim, Germany) as previously described $(24,25)$. Triplicate wells were measured for cell viability in each treatment group.

Cell apoptosis assay. Cells were transfected with $10 \mathrm{nM}$ siRNA or miRNA by reverse transfection and plated in 6-well plates at $3 \times 10^{4}$ cells per well. Cells were harvested $72 \mathrm{~h}$ after transfection by trypsinization and washed twice in cold PBS. Double staining with FITC-Annexin V and PI was carried out using the FITC Annexin V Apoptosis Detection Kit (BD Biosciences, Franklin Lakes, NJ, USA), according to the manufacturer's recommendations and analyzed within an hour 
A

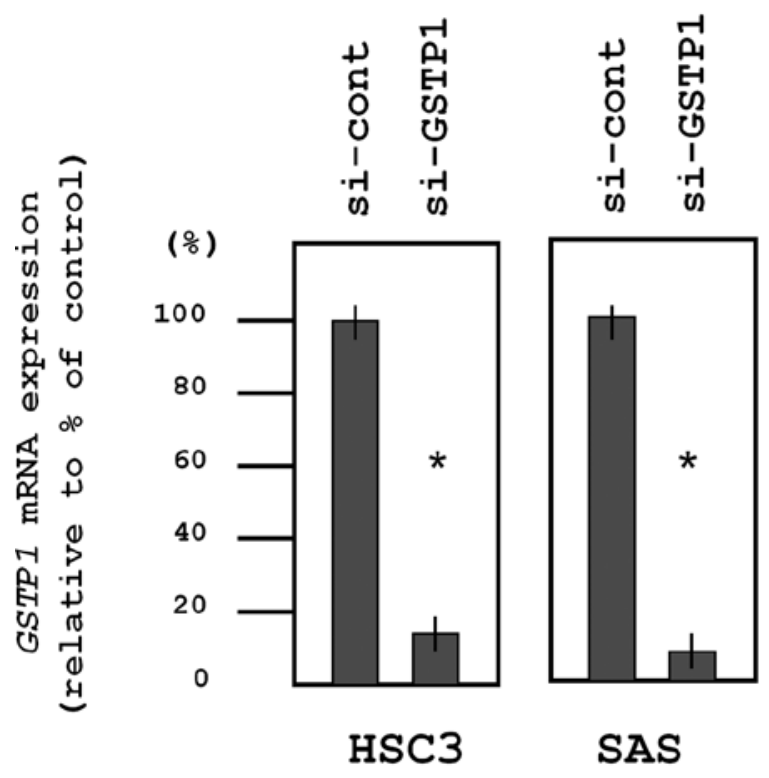

B

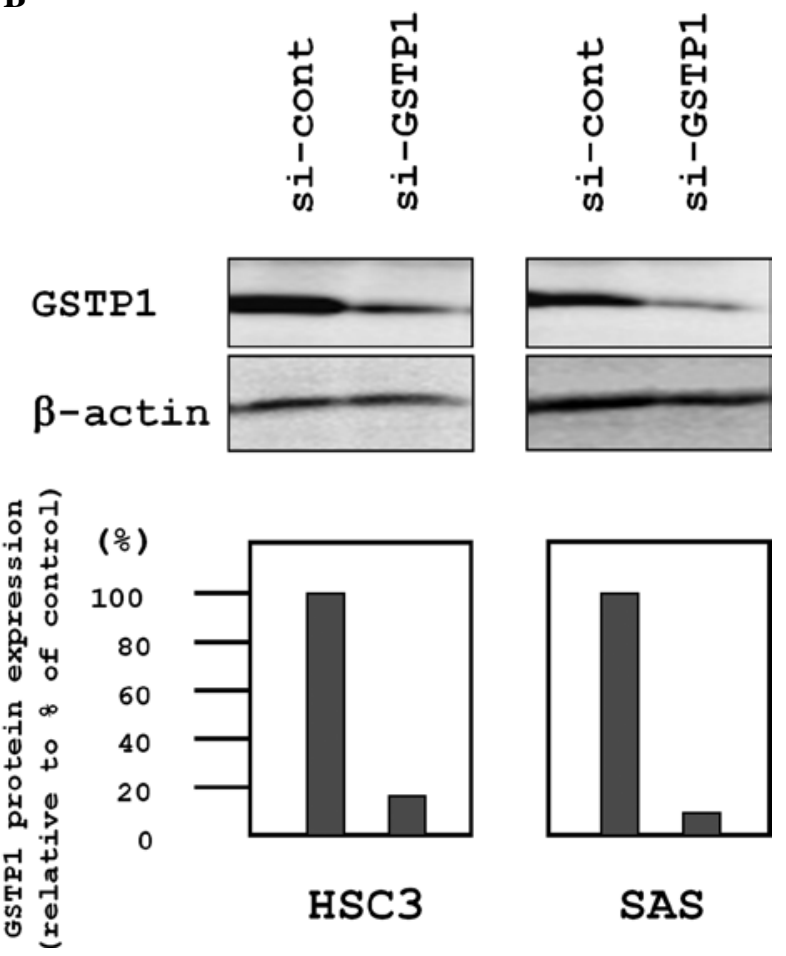

Figures 1. Regulation of GSTP1 expression in HNSCC cell lines (HSC3 and SAS) by si-GSTP1 transfection. (A) GSTP1 mRNA expression was repressed after $72 \mathrm{~h}$ of transfection with $10 \mathrm{nM}$ si-GSTP1 compared with control transfectants. ${ }^{*} \mathrm{P}<0.05$. (B) GSTP1 protein expression after $72 \mathrm{~h}$ transfection with si-GSTP1. $\beta$-actin was used as a loading control. The protein expression levels were also repressed in the transfectants.

by flow cytometry (FACScan ${ }^{\circledR}$; BD Biosciences). Cells were resolved into viable cells, dead cells, early apoptotic cells and apoptotic cells by CellQuest software (BD Biosciences). The percentages of early apoptotic cells in each experiment were compared. Experiments were performed in triplicate.

Plasmid construction and the dual-luciferase reporter assay. miRNA target sequences were inserted between the XhoIPmeI restriction sites in the 3'UTR of the hRluc gene in the psiCHECK $^{\mathrm{TM}}$-2 vector (C8021; Promega, Madison, WI, USA). Primer sequences for the full-length 3'UTR of GSTP1 mRNA (TAGGCGATCGCTCGAGGGGTTGGGGGGACTCTGA and TCTAGGTTTAAACTTTATTGGTCCTGGAGAAAGGA) were designed. SAS cells were transfected with $5 \mathrm{ng}$ of vector, $10 \mathrm{nM}$ miRNAs, and $1 \mu \mathrm{l}$ of Lipofectamine ${ }^{\mathrm{TM}} 2000$ (Invitrogen) in $100 \mu \mathrm{l}$ of Opti-MEM ${ }^{\mathrm{TM}}$ (Invitrogen). The activities of firefly and Renilla luciferases in cell lysates were determined with a dual-luciferase assay system (E1910; Promega). Normalized data were calculated as the quotient of Renilla/firefly luciferase activities.

\section{Results}

Effect of GSTP1 silencing on cell proliferation in HNSCC cell lines. To examine the effect of silencing of GSTP1, si-GSTP1 was transfected into HSC3 and SAS cell lines. The efficiency of both mRNA and protein silencing of GSTP1 were evaluated in the siRNA transfectant cell lines. The expression levels of both mRNA and protein were clearly reduced in the si-GSTPI transfectant cells (Fig. 1).
We monitored cellular proliferation after si-GSTP1 transfection in HSC3 and SAS cell lines. The XTT assay revealed that cell viability significantly decreased in a time-dependent manner in the si-GSTP1 transfectants in comparison with the si-control in both HSC3 and SAS cells (Fig. 2). In HSC3 cells, the cell growth of si-GSTP1 transfectants was $65.3 \%$ and $50.5 \%$ (both $\mathrm{P}<0.05$ ) of that seen in si-controls after $72 \mathrm{~h}$ and $96 \mathrm{~h}$, respectively. Similarly, in SAS cells, cell growth after $72 \mathrm{~h}$ and $96 \mathrm{~h}$ was $42.7 \%$, and $35.2 \%$ of control, respectively (both $\mathrm{P}<0.05$ ).

The effect of GSTP1 silencing on apoptosis was analyzed using flow cytometry. In HSC3 cells, GSTP1 silencing resulted in a 4.85-fold increase in the proportion of early apoptotic cells (Fig. 3, upper panels) while in SAS cells, it resulted in a 7.23-fold increase in the total proportion of early apoptotic cells after si-GSTP1 transfection (Fig. 3, lower panels).

GSTP1 as a target of post-transcriptional repression by $m i R-133 a$. Interestingly, GSTP1 3'UTR contains a predicted target sequence for $m i R-133 a$ suggesting it might function as a tumor suppressive miRNA. The expression levels of GSTP1 mRNA and GSTPl protein were markedly reduced in miR-133a transfectant cells when compared to miRNA-control transfectants (Fig. 4). This suggests that $m i R-133 a$ regulates GSTPI expression by cleavage or translational inhibition. We performed a luciferase reporter assay to determine whether $G S T P 1 \mathrm{mRNA}$ is an actual target site for $m i R-133 a$, as indicated by the TargetScan program (release 5.1, http://www.targetscan. org/). We constructed a vector encoding the full-length 3'UTR of GSTPI mRNA and found that the luminescence intensity 

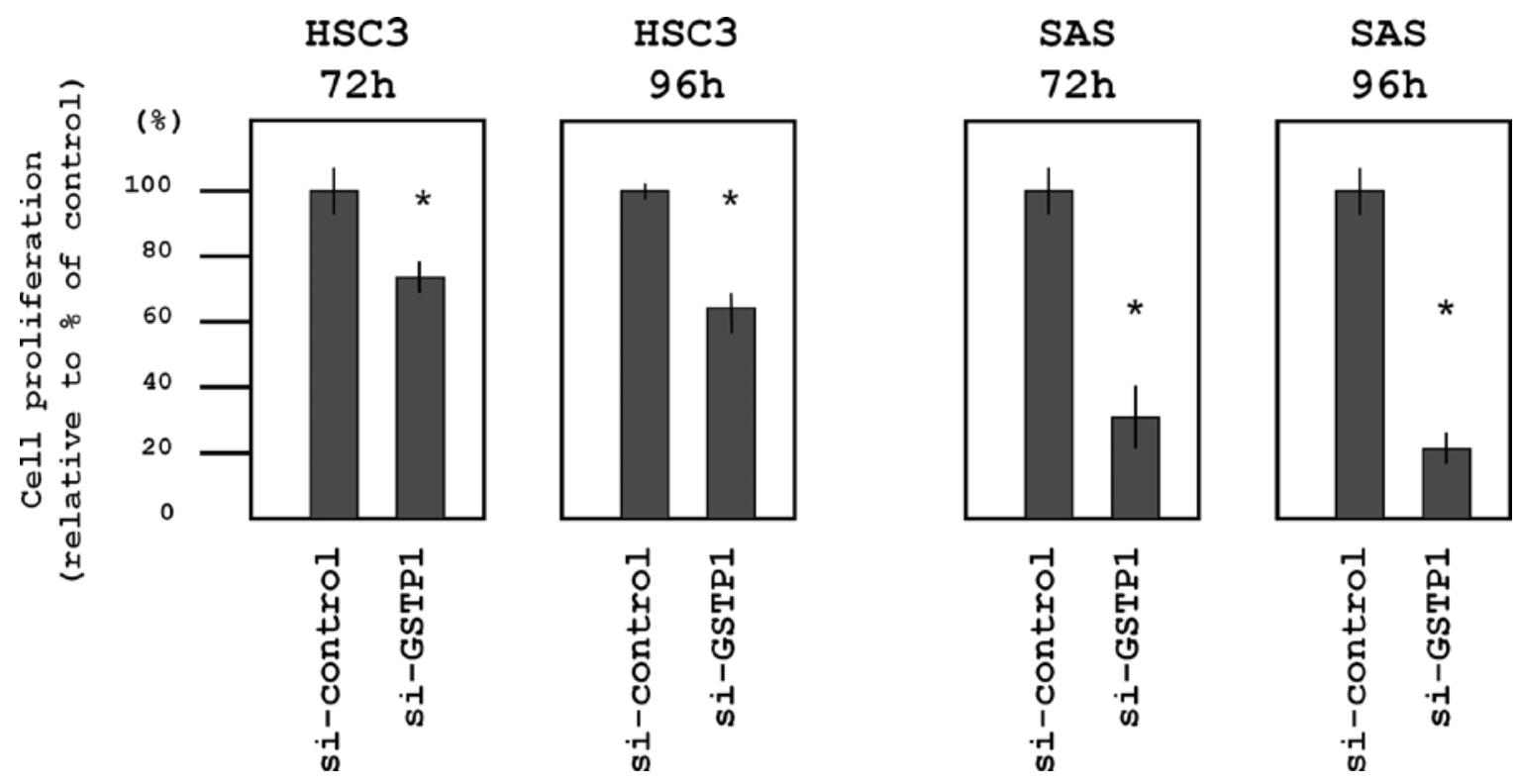

Figure 2. Effects of si-GSTP1 transfection on the proliferation of HNSCC cell lines, HSC3 and SAS, by XTT assays. Inhibition of cell growth was observed in HSC 3 and SAS cell lines $72 \mathrm{~h}$ or $96 \mathrm{~h}$ after transfection with $10 \mathrm{nM}$ of si-GSTP1 or control-siRNA. ${ }^{*} \mathrm{P}<0.05$.
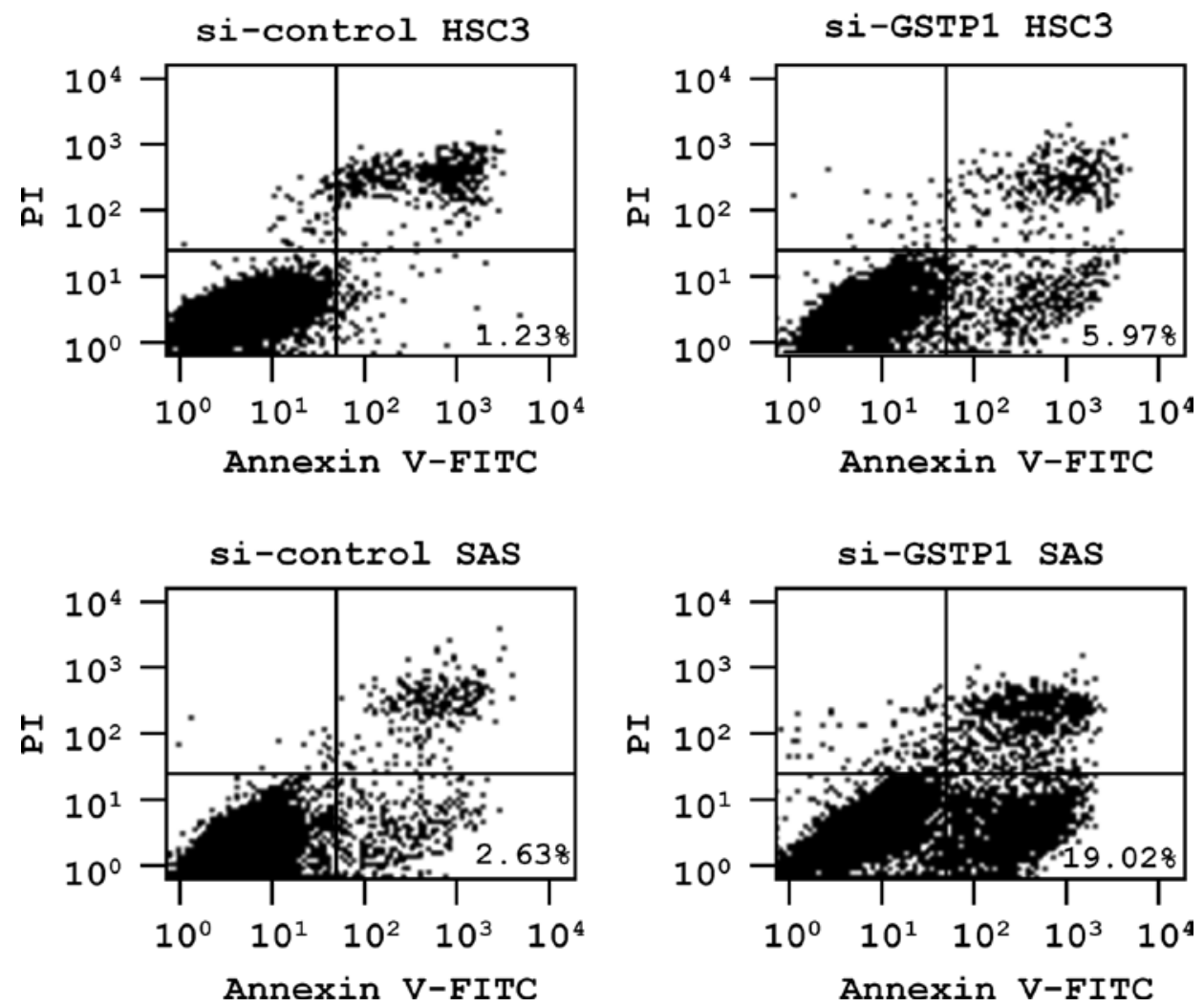

Figure 3. Flow cytometric analysis of si-GSTP1 transfected HSC3 and SAS cells. Apoptotic cells increased $72 \mathrm{~h}$ after transfection of cells with $10 \mathrm{nM}$ si-GSTP1.

was significantly lower $(\mathrm{P}<0.05)$ in the $m i R-133 a$ transfectant (Fig. 5).

Underexpression of $\mathrm{miR}-133 \mathrm{a}$ and overexpression of GSTPI protein in HNSCC clinical specimens. The expression levels of $m i R-133 a$ were evaluated using 20 HNSCC clinical speci- mens. Levels of $m i R-133 a$ were significantly lower $(\mathrm{P}=0.005)$ in cancerous tissues than in non-cancerous tissues (Fig. 6A). In contrast, the expression levels of GSTP1 protein were up-regulated in cancer cells as determined by immunohistochemistry (Fig. 6B). Representative data of twenty HNSCC patients are described in Table I. 
A

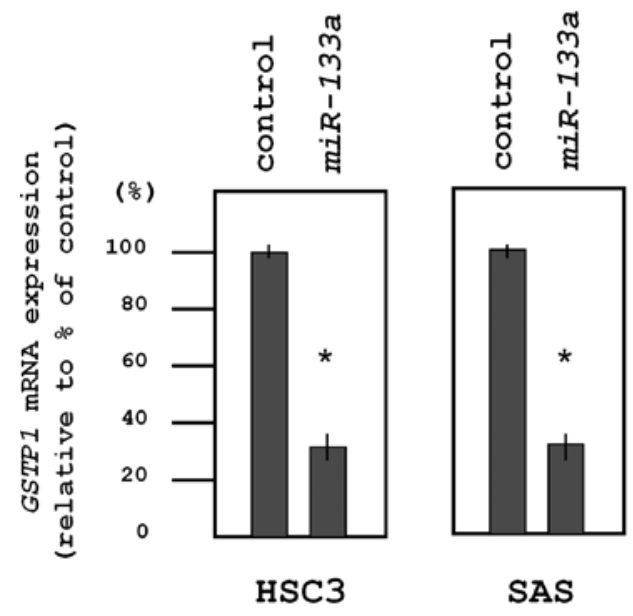

B

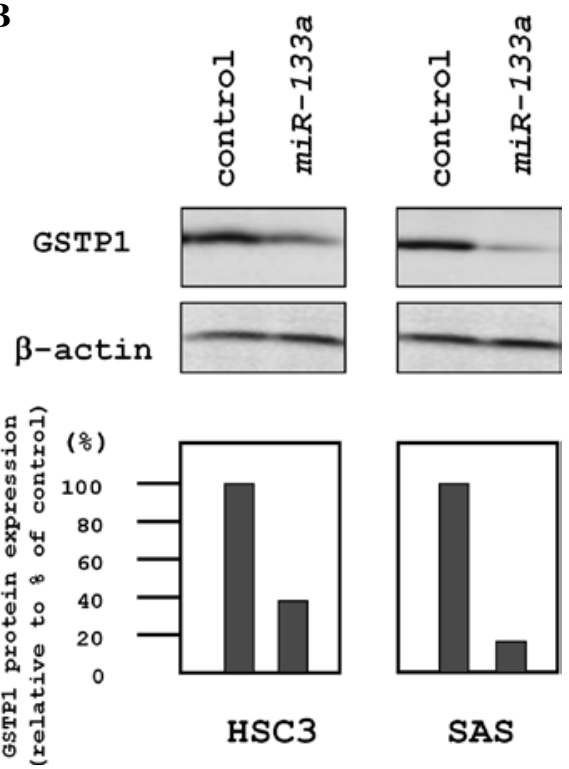

Figures 4. Regulation of GSTP1 expression in HNSCC cells by $m i R-133 a$ transfection. (A) GSTP1 mRNA expression $72 \mathrm{~h}$ after transfection of $m i R-133 a$. GSTP1 mRNA expression was reduced in both $m i R$-133a transfectants. The results were normalized to glyceraldehyde-3-phosphate dehydrogenase (GAPDH) expression. ${ }^{*} \mathrm{P}<0.05$. (B) GSTP1 protein expression was analyzed by Western blot analysis $72 \mathrm{~h}$ after transfection of $m i R-133 a$. GSTP1 protein expression was also reduced in $m i R-133 a$ transfectants. The membranes were blotted with anti-GSTP1 IgG and anti- $\beta$-actin was used as a loading control. The density of each protein band was quantified using NIH-ImageJ. The results were standardized against the levels of $\beta$-actin.

GSTP1 3'UTR
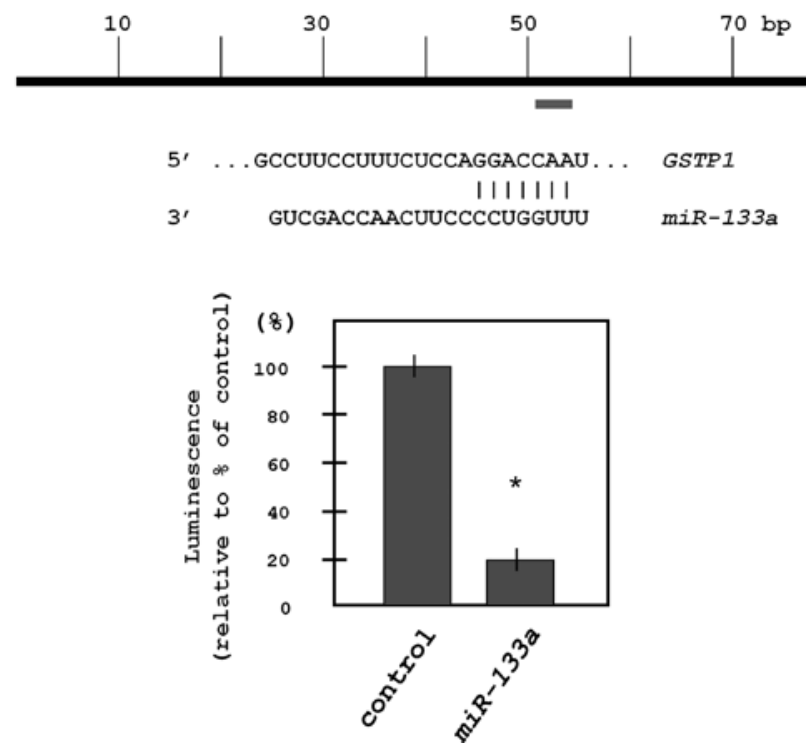

Figure 5. miR-133a regulates GSTP1 expression in the SAS cell line at the mRNA and post-transcriptional level by targeting the 3'UTR of GSTPI mRNA. Schema for the putative conserved binding site of miR-133a (upper panel). The putative conserved target site in the GSTP1 3'UTR was identified with the TargetScan database. SAS cells were transfected with $5 \mathrm{ng}$ of GSTP1 $3^{\prime}$ UTR in a vector construct or $10 \mathrm{nM}$ of miRNA or negative control. Renilla luciferase activity was measured following a $24 \mathrm{~h}$ transfection. The results were normalized against firefly luciferase values (lower panel). " $\mathrm{P}<0.05$.

\section{Discussion}

GSTs are phase II detoxification enzymes that catalyze the conjugation of electrophilic compounds with reduced glutathione (3). Among the GSTs, GSTP1 is frequently overexpressed in many cancers (5-10). Recently, we reported that mRNA levels of GSTP1 were highly expressed in HNSCC tissues compared to adjacent non-cancerous tissues (4). Furthermore, GSTP1 has been mapped to human chromosome 11q13 and this region is frequently altered in human HNSCC clinical specimens $(26,27)$. Expression of GSTP1 mRNA has been correlated with chromosomal alterations in HNSCC (4). However, the biological result of GSTPI overexpression in HNSCC remains unclear.

In this study, we explored silencing of GSTP1 in two HNSCC cell lines, HSC 3 and SAS. The analysis showed that GSTP1 plays an oncogenic role by inhibiting apoptosis. Enhanced GSTP1 expression might influence tumor growth by inhibition of apoptosis pathways, as reported in hepatic carcinoma, prostate cancer, small cell lung carcinoma, and myeloid leukemia (28-31). It has been shown that GSTPI protein interacts with c-Jun $\mathrm{NH}_{2}$-terminal kinase (JNK) and tumor necrosis factor receptor-associated factor 2 (TRAF2), and suppresses the induction of apoptosis (32). In HEK293 cells, overexpression of GSTP1 inhibited both MEKK1- and etoposide-induced apoptosis, and inhibited pro-caspase-3 activation and PARP cleavage (33). In clinical specimens of bladder cancer, BCL2 protein expression and high GSTP1 expression were positively correlated (34). These findings are consistent with our report. The molecular interplay between GSTPI and the apoptotic cascade could provide new approaches for the development of cancer therapy.

Recently, it was reported that wild-type p53 regulates GSTP1 expression and protects the genome from alkylating and free radical-generating compounds (35). Thus, it was of interest to determine which genes regulated GSTP1. We focused on miRNAs, an abundant class of small non-coding RNAs approximately 19-22 nucleotides in length that function as negative regulators of gene expression by antisense compli- 
Table I. Clinical features of HNSCC patients.

\begin{tabular}{llllllll}
\hline No. & Gender & Age & Location & Differentiation & $\mathrm{T}$ & $\mathrm{N}$ & $\mathrm{M}$ \\
\hline 1 & Male & 60 & Oral cavity & Well & 2 & 0 & 0 \\
2 & Male & 60 & Oral cavity & Moderate & 4 & $2 \mathrm{c}$ & 0 \\
3 & Male & 66 & Oral cavity & Moderate & 2 & 0 & 0 \\
4 & Female & 73 & Oral cavity & Well & 1 & 0 & 0 \\
5 & Male & 64 & Oral cavity & Well & 1 & 0 & 0 \\
6 & Male & 66 & Oral cavity & Well & 3 & 0 & 0 \\
7 & Male & 58 & Oral cavity & Moderate & 1 & 0 & 0 \\
8 & Male & 73 & Oral cavity & Poor & 3 & 1 & 0 \\
9 & Female & 38 & Oral cavity & Well & 2 & $2 \mathrm{~b}$ & 0 \\
10 & Male & 66 & Larynx & Well & $4 \mathrm{a}$ & 0 & 0 \\
11 & Male & 69 & Larynx & Well & 3 & 0 & 0 \\
12 & Male & 57 & Larynx & Moderate & $4 \mathrm{a}$ & 0 & 0 \\
13 & Male & 77 & Oropharynx & Moderate & $4 \mathrm{~b}$ & $2 \mathrm{~b}$ & 0 \\
14 & Male & 52 & Oropharynx & Moderate & 3 & $2 \mathrm{a}$ & 0 \\
15 & Female & 65 & Oropharynx & Well & $4 \mathrm{a}$ & $2 \mathrm{~b}$ & 0 \\
16 & Female & 65 & Hypopharynx & Well & $4 \mathrm{a}$ & 0 & 0 \\
17 & Male & 68 & Hypopharynx & Poor & 4 & 1 & 0 \\
18 & Male & 68 & Hypopharynx & Moderate & 4 & 1 & 0 \\
19 & Male & 66 & Hypopharynx & Moderate & 2 & $2 \mathrm{c}$ & 0 \\
20 & Female & 74 & Hypopharynx & Well & $4 \mathrm{a}$ & 0 & 0 \\
\hline
\end{tabular}

A

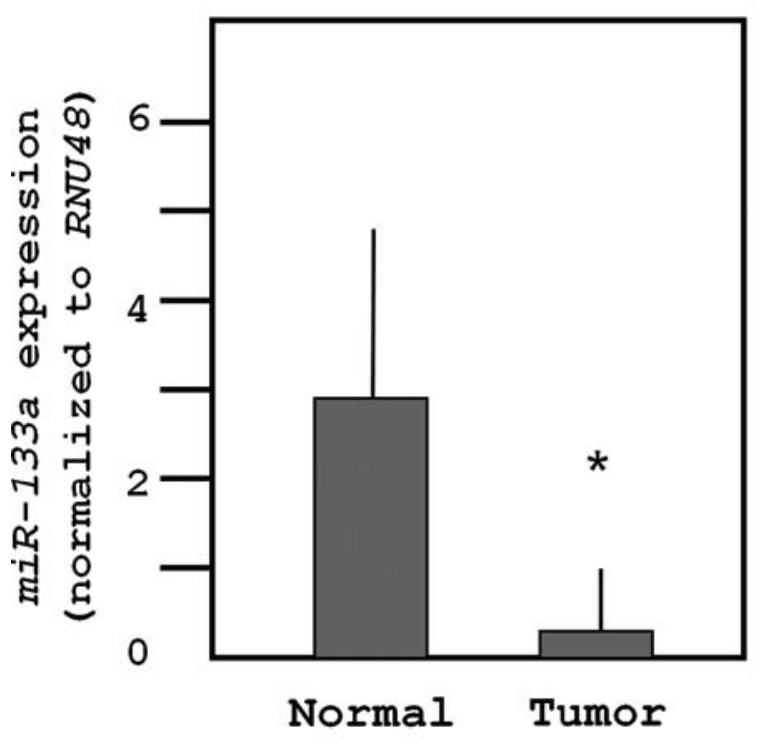

B

GSTP1 expression

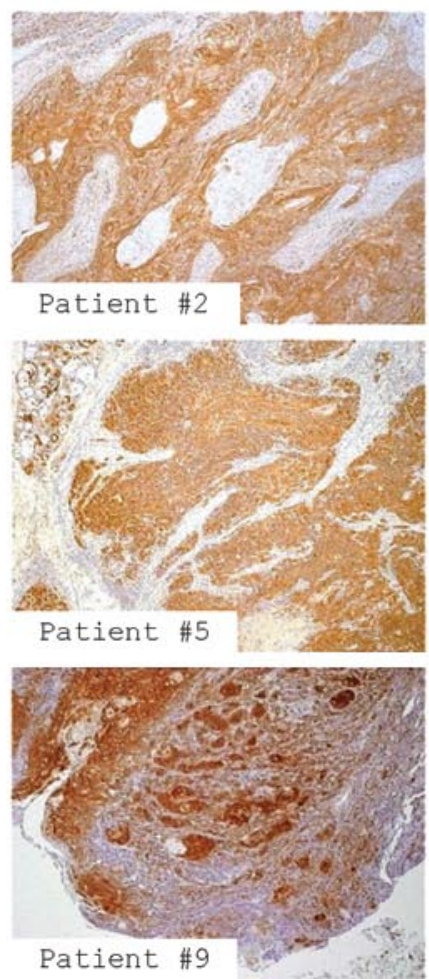

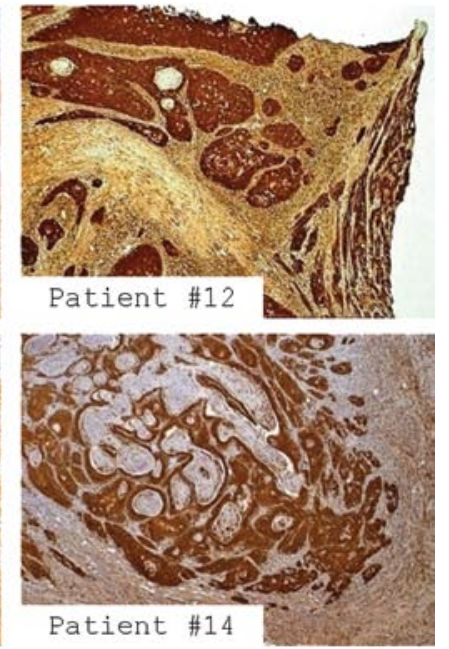

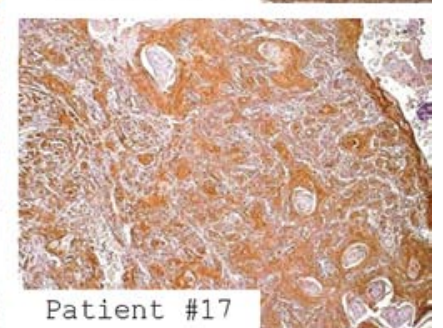

Figure 6. Expression levels of $m i R-133 a$ and GSTP1 protein in HNSCC clinical specimens. (A) $m i R-133 a$ expression in HNSCC specimens by real-time RT-PCR. RNU48 was used as the internal control. * $\mathrm{P}=0.005$. (B) GSTP1 protein expression in HNSCC specimens. Typical immunohistochemical results are shown (patients $2,5,9,12,14$, and 17). 
mentarity to specific messenger RNAs (13). A database search (TargetScan program: release 5.1, April 2009, http://www. targetscan.org/) revealed that miR-133a might target GSTPI mRNA. Our study proved that GSTPI expression was regulated through direct binding to a specific site in the 3'UTR.

Several studies indicated that $m i R-133 a$ controls cardiac hypertrophy, and it is significantly down-regulated in hypertrophic and failing hearts (36). Targets of $m i R-133 a$ are the Ras homolog gene family member $\mathrm{A}(\mathrm{RHOA})$ and the cell division cycle 42 (CDC42) genes (37,38). Expression of miR-133a is reduced in many cancers, including HNSCC and oral cancer, suggesting its role as a tumor suppressive miRNA $(19-21,24,39)$. More recently, our studies demonstrated that miR-133a transfection of cancer cells significantly reduced cell proliferation, migration and invasion in bladder cancer, and esophageal squamous cell carcinoma. miR-133a directly regulated several oncogenic genes, such as FSCN1 and LASP1 $(23,24,40)$. Other groups also found that $m i R-133 a$ inhibited proliferation and induced apoptosis in squamous cell carcinoma of the tongue, and directly controlled pyruvate kinase type M2 gene expression (39). Thus, miR-133a regulates many oncogenic genes. How GSTP1 overexpression changes in many types of cancers is still unclear, but one possible mechanism is through regulation by $m i R-133 a$.

Together, our findings demonstrate that the tumor suppressor $m i R-133 a$, regulates $G S T P 1$ expression and that overexpression of GSTPI increases cell proliferation by inhibiting apoptotic pathways in HNSCC. The therapeutic implications of these findings should be futher exploited towards the development of future HNSCC treatments.

\section{Acknowledgements}

This study was supported by the Ministry of Education, Science, Sports and Culture, Grant-in-Aid for Scientific Research (C), 21592187. This study was also supported in part by the Society for Promotion of International Oto-RhinoLaryngology (SPIO), Japan.

\section{References}

1. Jemal A, Siegel R, Ward E, Murray T, Xu J, Smigal C and Thun MJ: Cancer statistics, 2006. CA Cancer J Clin 56: 106-130, 2006.

2. Hardisson D: Molecular pathogenesis of head and neck squamous cell carcinoma. Eur Arch Otorhinolaryngol 260: 502-508, 2003.

3. Sheehan D, Meade G, Foley VM and Dowd CA: Structure, function and evolution of glutathione transferases: implications for classification of non-mammalian members of an ancient enzyme superfamily. Biochem J 360: 1-16, 2001.

4. Sugimoto T, Seki N, Shimizu S, Kikkawa N, Tsukada J, Shimada H, Sasaki K, Hanazawa T, Okamoto Y and Hata A: The galanin signaling cascade is a candidate pathway regulating oncogenesis in human squamous cell carcinoma. Genes Chromosomes Cancer 48: 132-142, 2009.

5. Moscow JA, Fairchild CR, Madden MJ, Ransom DT, Wieand HS, O'Brien EE, Poplack DG, Cossman J, Myers CE and Cowan KH: Expression of anionic glutathione-S-transferase and P-glycoprotein genes in human tissues and tumors. Cancer Res 49: 1422-1428, 1989.

6. Sato K: Glutathione transferases as markers of preneoplasia and neoplasia. Adv Cancer Res 52: 205-255, 1989.

7. Howie AF, Forrester LM, Glancey MJ, Schlager JJ, Powis G, Beckett GJ, Hayes JD and Wolf CR: Glutathione S-transferase and glutathione peroxidase expression in normal and tumour human tissues. Carcinogenesis 11: 451-458, 1990.
8. Ranganathan $\mathrm{S}$ and Tew KD: Immunohistochemical localization of glutathione S-transferases alpha, mu, and pi in normal tissue and carcinomas from human colon. Carcinogenesis 12: 23832387, 1991

9. Ali-Osman F, Brunner JM, Kutluk TM and Hess K: Prognostic significance of glutathione S-transferase pi expression and subcellular localization in human gliomas. Clin Cancer Res 3: 2253-2261, 1997.

10. Miyanishi K, Takayama T, Ohi M, Hayashi T, Nobuoka A, Nakajima T, Takimoto R, Kogawa K, Kato J, Sakamaki S and Niitsu Y: Glutathione S-transferase-pi overexpression is closely associated with K-ras mutation during human colon carcinogenesis. Gastroenterology 121: 865-874, 2001.

11. Cotton SC, Sharp L, Little J and Brockton N: Glutathione S-transferase polymorphisms and colorectal cancer: a HuGE review. Am J Epidemiol 151: 7-32, 2000.

12. Tew KD, Dutta S and Schultz M: Inhibitors of glutathione S-transferases as therapeutic agents. Adv Drug Deliv Rev 26: 91-104, 1997.

13. Bartel DP: MicroRNAs: genomics, biogenesis, mechanism, and function. Cell 116: 281-297, 2004.

14. Filipowicz W, Bhattacharyya SN and Sonenberg N: Mechanisms of post-transcriptional regulation by microRNAs: are the answers in sight? Nat Rev Genet 9: 102-114, 2008.

15. Kloosterman WP and Plasterk RH: The diverse functions of microRNAs in animal development and disease. Dev Cell 11: 441-450, 2006.

16. Hwang HW and Mendell JT: MicroRNAs in cell proliferation, cell death, and tumorigenesis. Br J Cancer 94: 776-780, 2006.

17. Lu J, Getz G, Miska EA, Alvarez-Saavedra E, Lamb J, Peck D, Sweet-Cordero A, Ebert BL, Mak RH, Ferrando AA, Downing JR, Jacks T, Horvitz HR and Golub TR: MicroRNA expression profiles classify human cancers. Nature 435: 834-838, 2005.

18. Calin GA and Croce CM: MicroRNA signatures in human cancers. Nat Rev Cancer 6: 857-866, 2006.

19. Arndt GM, Dossey L, Cullen LM, Lai A, Druker R, Eisbacher M, Zhang C, Tran N, Fan H, Retzlaff K, Bittner A and Raponi M: Characterization of global microRNA expression reveals oncogenic potential of miR-145 in metastatic colorectal cancer. BMC Cancer 9: 374, 2009.

20. Childs G, Fazzari M, Kung G, Kawachi N, Brandwein-Gensler M, McLemore M, Chen Q, Burk RD, Smith RV, Prystowsky MB, Belbin TJ and Schlecht NF: Low-level expression of microRNAs let-7d and miR-205 are prognostic markers of head and neck squamous cell carcinoma. Am J Pathol 174: 736-745, 2009.

21. Ichimi T, Enokida H, Okuno Y, Kunimoto R, Chiyomaru T, Kawamoto K, Kawahara K, Toki K, Kawakami K, Nishiyama K, Tsujimoto G, Nakagawa M and Seki N: Identification of novel microRNA targets based on microRNA signatures in bladder cancer. Int J Cancer 125: 345-352, 2009.

22. Wong TS, Liu XB, Wong BY, Ng RW, Yuen AP and Wei WI: Mature miR-184 as potential oncogenic microRNA of squamous cell carcinoma of tongue. Clin Cancer Res 14: 2588-2592, 2008.

23. Chiyomaru T, Enokida H, Tatarano S, Kawahara K, Uchida Y, Nishiyama K, Fujimura L, Kikkawa N, Seki N and Nakagawa M: miR-145 and miR-133a function as tumour suppressors and directly regulate FSCN1 expression in bladder cancer. Br J Cancer 102: 883-891, 2010.

24. Kano M, Seki N, Kikkawa N, Fujimura L, Hoshino I, Akutsu Y, Chiyomaru T, Enokida H, Nakagawa $M$ and Matsubara $H$ : $m i R-145, m i R-133 a$ and $m i R-133 b$ : Tumor suppressive miRNAs target FSCN1 in esophageal squamous cell carcinoma. Int J Cancer 127: 2804-2814, 2010.

25. Kikkawa N, Hanazawa T, Fujimura L, Nohata N, Suzuki H, Chazono H, Sakurai D, Horiguchi S, Okamoto Y, Seki N: miR-489 is a tumour-suppressive miRNA target PTPN11 in hypopharyngeal squamous cell carcinoma (HSCC). Br J Cancer 103: 877-884, 2010.

26. Komatsu Y, Hibi K, Kodera Y, Akiyama S, Ito K and Nakao A: TAOS1, a novel marker for advanced esophageal squamous cell carcinoma. Anticancer Res 26: 2029-2032, 2006.

27. Jarvinen AK, Autio R, Kilpinen S, Saarela M, Leivo I, Grenman R, Makitie AA and Monni O: High-resolution copy number and gene expression microarray analyses of head and neck squamous cell carcinoma cell lines of tongue and larynx. Genes Chromosomes Cancer 47: 500-509, 2008.

28. Duvoix A, Morceau F, Delhalle S, Schmitz M, Schnekenburger M, Galteau MM, Dicato M and Diederich M: Induction of apoptosis by curcumin: mediation by glutathione S-transferase P1-1 inhibition. Biochem Pharmacol 66: 1475-1483, 2003. 
29. Hokaiwado N, Takeshita F, Naiki-Ito A, Asamoto M, Ochiya T and Shirai T: Glutathione S-transferase Pi mediates proliferation of androgen-independent prostate cancer cells. Carcinogenesis 29: 1134-1138, 2008.

30. Turella P, Cerella C, Filomeni G, Bullo A, De Maria F, Ghibelli L, Ciriolo MR, Cianfriglia M, Mattei M, Federici G, Ricci G and Caccuri AM: Proapoptotic activity of new glutathione S-transferase inhibitors. Cancer Res 65: 3751-3761, 2005.

31. Dang DT, Chen F, Kohli M, Rago C, Cummins JM and Dang LH: Glutathione S-transferase pil promotes tumorigenicity in HCT116 human colon cancer cells. Cancer Res 65: 9485-9494, 2005.

32. Wu Y, Fan Y, Xue B, Luo L, Shen J, Zhang S, Jiang Y and Yin Z: Human glutathione S-transferase P1-1 interacts with TRAF2 and regulates TRAF2-ASK1 signals. Oncogene 25: 5787-5800, 2006.

33. Zhao X, Fan Y, Shen J, Wu Y and Yin Z: Human glutathione S-transferase P1 suppresses MEKK1-mediated apoptosis by regulating MEKK1 kinase activity in HEK293 cells. Mol Cells 21: 395-400, 2006.

34. Pljesa-Ercegovac M, Savic-Radojevic A, Dragicevic D, Mimic-Oka J, Matic M, Sasic T, Pekmezovic T, Vuksanovic A and Simic T: Enhanced GSTP1 expression in transitional cell carcinoma of urinary bladder is associated with altered apoptotic pathways. Urol Oncol: Jan 20, 2009 (Epub ahead of print) PMID: 19162514
35. Smeyne M, Boyd J, Raviie Shepherd K, Jiao Y, Pond BB, Hatler M, Wolf R, Henderson C and Smeyne RJ: GSTpi expression mediates dopaminergic neuron sensitivity in experimental parkinsonism. Proc Natl Acad Sci USA 104: 1977-1982, 2007.

36. Meder B, Katus HA and Rottbauer W: Right into the heart of microRNA-133a. Genes Dev 22: 3227-3231, 2008.

37. Chiba Y, Tanabe M, Goto K, Sakai H and Misawa M: Downregulation of miR-133a contributes to up-regulation of Rhoa in bronchial smooth muscle cells. Am J Respir Crit Care Med 180: 713-719, 2009.

38. Care A, Catalucci D, Felicetti F, Bonci D, Addario A, Gallo P, Bang ML, Segnalini P, Gu Y, Dalton ND, Elia L, Latronico MV, Hoydal M, Autore C, Russo MA, Dorn GW II, Ellingsen O, Ruiz-Lozano P, Peterson KL, Croce CM, Peschle C and Condorelli G: MicroRNA-133 controls cardiac hypertrophy. Nat Med 13: 613-618, 2007.

39. Wong TS, Liu XB, Ho AC, Yuen AP, Ng RW and Wei WI: Identification of pyruvate kinase type M2 as potential oncoprotein in squamous cell carcinoma of tongue through microRNA profiling. Int J Cancer 123: 251-257, 2008.

40. Chiyomaru T, Enokida H, Kawakami K, Tatarano S, Uchida Y, Kawahara K, Nishiyama K, Seki N and Nakagawa M: Functional role of LASP1 in cell viability and its regulation by microRNAs in bladder cancer. Urol Oncol: Sep 14, 2010 (Epub ahead of print). 